\title{
Endoscopic Techniques for Gallbladder Drainage: Never without My Endoscopic Ultrasound
}

\author{
Gianmarco Marocchi, Andrea Lisotti, and Pietro Fusaroli \\ Gastrointestinal Unit, Department of Medical and Surgical Sciences, Hospital of Imola, University of Bologna, Imola, Italy
}

Article Info

Received February 14, 2021

Accepted February 22, 2021

Published online May 7, 2021

Corresponding Author

Gianmarco Marocchi

ORCID https://orcid.org/0000-0001-9925-3486

E-mail gianmarco.marocchi2@gmail.com
To the Editor:

We read with great interest the article by Yoshida et al. ${ }^{1}$ published online in January 2021, that described cholangioscopic assistance for endoscopic transpapillary gallbladder drainage (ETGBD) in 101 high-risk surgical patients with acute cholecystitis. The authors reported that the optional use of cholangioscopy could lead to a significantly higher technical success rate than the use of conventional ETGBD alone $94.1 \%$ vs 72\%). A 4-step classification was also developed to categorize the factors that could complicate ETGBD. The authors conclude that the application of cholangioscopic assistance in a coordinated manner, based on the 4-step classification, represents a valid strategy for improving the success rate of ETGBD, in particular in the early stages, when there is a greater probability of technical failure. However, as stated by the authors, ETGBD is a challenging procedure that requires advanced endoscopic techniques and carries the possibility of adverse events, such as post-ERCP pancreatitis. Furthermore, advancing the guidewire in the presence of tortuosity of the cystic duct remains an unsolved issue, even with cholangioscopic assistance.

Endoscopic ultrasound-guided gallbladder drainage (EUS-GBD) represents a valid alternative that can overcome the abovementioned problems. EUS-GBD is a well described procedure in high-risk surgical patients with acute cholecystitis, either as a bridge to surgery or as a definitive therapy. ${ }^{2-6}$ Two recent systematic reviews and metaanalyses reported a significantly higher clinical success rate with EUS-GBD than with $\mathrm{ETGBD}^{7}$ and percutaneous gallbladder drainage, ${ }^{8}$ with similar rates of adverse events between the procedures. In the past year, faced with issues related to the COVID-19 (coronavirus disease 2019) pandemic, such as a shortage of operating rooms and intensive care unit beds, our group suggested that EUS-GBD should be considered the intervention of choice in patients with acute cholecystitis to obtain a definitive treatment and allow rapid patient discharge. ${ }^{9}$ We reported the case of an 80 -year-old woman with sepsis due to acute cholecystitis that was successfully managed outside the operating room and intensive care unit. In that patient, gallbladder drainage was achieved by the EUS-guided placement of a 10-mm electrocautery-enhanced lumen-apposing metal stent (LAMS). The procedure lasted 20 minutes and no adverse events occurred. The patient was discharged 4 hours later. ${ }^{10}$ Furthermore, we previously reported that in most cases, EUS-GBD could be performed without general anesthesia, avoiding intensive care unit admission and reducing the occurrence of anesthesiology-related adverse events. ${ }^{11,12}$ Adverse effects of EUS-GBD, such as bleeding and perforation, have been described in a small percentage of cases. ${ }^{8}$ In our experience, a conspicuous bleeding due to the puncture of a gallbladder wall arteriole following the insertion of a LAMS was successfully rescued by the deployment of a second LAMS close to the bleeding point, leading to mechanical hemostasis. ${ }^{13}$ In that case, contrast-enhanced harmonic 
EUS (CH-EUS) played a central role. Although CH-EUS has already been shown to be a useful tool in the diagnostic phase, ${ }^{14-16}$ increasing exexperience with $\mathrm{CH}$-EUS guided therapeutic interventions is being reported. In the aforementioned case, CH-EUS was crucial for the identification of the feeding vessel, allowing the deployment of the second LAMS in a targeted manner. Furthermore, the absence of spreading of the contrast dye demonstrated the success of the rescue strategy.

As was brilliantly demonstrated by Yoshida et al., ${ }^{1}$ some technological developments can be adopted to simplify complex interventional procedures. In addition to the introduction of dedicated devices for EUS-guided drainage that allow the spread of pancreatic fluid collection or biliary drainage, ${ }^{17-19}$ it was found that the use of a single-operator digital cholangioscope could improve the technical and clinical outcomes of ETGBD. Finally, several drainage strategies are available for use in high-risk surgical patients with acute cholecystitis; in our opinion, EUS-GBD seems to offer some marked advantages over ETGBD and percutaneous gallbladder drainage, ${ }^{20,21}$ providing a definitive therapy with high rates of technical and clinical success while requiring less anesthesia and a shorter duration of hospitalization.

\section{CONFLICTS OF INTEREST}

No potential conflict of interest relevant to this article was reported.

\section{ORCID}

Gianmarco Marocchi

https://orcid.org/0000-0001-9925-3486

Andrea Lisotti https://orcid.org/0000-0002-7724-7402

Pietro Fusaroli https://orcid.org/0000-0002-4397-9314

\section{REFERENCES}

1. Yoshida M, Naitoh I, Hayashi K, et al. Four-step classification of endoscopic transpapillary gallbladder drainage and the practical efficacy of cholangioscopic assistance. Gut Liver 2021;15:476-485.

2. Itoi T, Binmoeller KF, Shah J, et al. Clinical evaluation of a novel lumen-apposing metal stent for endosonographyguided pancreatic pseudocyst and gallbladder drainage (with videos). Gastrointest Endosc 2012;75:870-876.

3. Dollhopf M, Larghi A, Will U, et al. EUS-guided gallbladder drainage in patients with acute cholecystitis and high surgical risk using an electrocautery-enhanced lumen-apposing metal stent device. Gastrointest Endosc 2017;86:636-643.

4. Fusaroli P, Jenssen C, Hocke M, et al. EFSUMB Guidelines on Interventional Ultrasound (INVUS), Part V-EUS-Guided Therapeutic Interventions (short version). Ultraschall Med 2016;37:412-420.

5. Mori Y, Itoi T, Baron TH, et al. Tokyo guidelines 2018: management strategies for gallbladder drainage in patients with acute cholecystitis (with videos). J Hepatobiliary Pancreat Sci 2018;25:87-95.

6. Fusaroli P, Serrani M, Lisotti A, D'Ercole MC, Ceroni L, Caletti G. Performance of the forward-view echoendoscope for pancreaticobiliary examination in patients with status post-upper gastrointestinal surgery. Endosc Ultrasound 2015;4:336-341.

7. Krishnamoorthi R, Jayaraj M, Thoguluva Chandrasekar V, et al. EUS-guided versus endoscopic transpapillary gallbladder drainage in high-risk surgical patients with acute cholecystitis: a systematic review and meta-analysis. Surg Endosc 2020;34:1904-1913.

8. Mohan BP, Khan SR, Trakroo S, et al. Endoscopic ultrasound-guided gallbladder drainage, transpapillary drainage, or percutaneous drainage in high risk acute cholecystitis patients: a systematic review and comparative meta-analysis. Endoscopy 2020;52:96-106.

9. Lisotti A, Bacchilega I, Linguerri R, Fusaroli P. Endoscopic ultrasound-guided gallbladder drainage as a strategy to overcome shortage of operating rooms and intensive care unit beds during Covid-19 crisis. Endoscopy 2020;52:E263-E264.

10. Lisotti A, Fusaroli P. EUS-guided gallbladder drainage during a pandemic crisis: how the COVID-19 outbreak could impact interventional endoscopy. Dig Liver Dis 2020;52:613614.

11. Lisotti A, Linguerri R, Bacchilega I, Cominardi A, Marocchi G, Fusaroli P. EUS-guided gallbladder drainage in high-risk surgical patients with acute cholecystitis-procedure outcomes and evaluation of mortality predictors. Surg Endosc. Epub 2021 Jan 28. https://doi.org/10.1007/s00464-02108318-z.

12. Fusaroli P, Serrani M, Sferrazza S, Linguerri R, Jovine E, Lisotti A. Elective cholecystectomy after reversal of septic shock using multimodality endoscopic gallbladder drainage. Endoscopy 2018;50:E299-E300.

13. Lisotti A, Cominardi A, Bacchilega I, Fusaroli P. Failed endoscopic ultrasound-guided gallbladder drainage due to severe bleeding immediately rescued by redo-drainage under contrast-harmonic guidance. Endoscopy 2020;52:517-519.

14. Fusaroli P, D'Ercole MC, De Giorgio R, Serrani M, Caletti G. Contrast harmonic endoscopic ultrasonography in the characterization of pancreatic metastases (with video). Pancreas 
2014;43:584-587.

15. Kamata K, Takenaka M, Kitano M, et al. Contrast-enhanced harmonic endoscopic ultrasonography for differential diagnosis of localized gallbladder lesions. Dig Endosc 2018;30:98-106.

16. Kamata K, Takenaka M, Kitano M, et al. Contrast-enhanced harmonic endoscopic ultrasonography for differential diagnosis of submucosal tumors of the upper gastrointestinal tract. J Gastroenterol Hepatol 2017;32:1686-1692.

17. Guo J, Giovannini M, Sahai AV, et al. A multi-institution consensus on how to perform EUS-guided biliary drainage for malignant biliary obstruction. Endosc Ultrasound 2018;7:356-365.

18. Guo J, Saftoiu A, Vilmann P, et al. A multi-institutional consensus on how to perform endoscopic ultrasound-guided peri-pancreatic fluid collection drainage and endoscopic necrosectomy. Endosc Ultrasound 2017;6:285-291.

19. Fusaroli P, Kypraios D, Eloubeidi MA, Caletti G. Levels of evidence in endoscopic ultrasonography: a systematic review. Dig Dis Sci 2012;57:602-609.

20. Teoh AYB, Kitano M, Itoi T, et al. Endosonography-guided gallbladder drainage versus percutaneous cholecystostomy in very high-risk surgical patients with acute cholecystitis: an international randomised multicentre controlled superiority trial (DRAC 1). Gut 2020;69:1085-1091.

21. Luk SW, Irani S, Krishnamoorthi R, Wong Lau JY, Wai Ng EK, Teoh AY. Endoscopic ultrasound-guided gallbladder drainage versus percutaneous cholecystostomy for high risk surgical patients with acute cholecystitis: a systematic review and meta-analysis. Endoscopy 2019;51:722-732. 